\title{
Modelling and Optimization of the Last Two Stages of an Environmentally-Compatible TCF Bleaching Sequence
}

\author{
Tamara Llano, ${ }^{a}$ Carlos Arce, ${ }^{\mathrm{a}}$ Gema Ruiz, ${ }^{\mathrm{a}}$ Naveen Chenna, ${ }^{\mathrm{b}}$ and Alberto $\mathrm{Coz}{ }^{\mathrm{a}, *}$ \\ A totally chlorine free (TCF) bleaching sequence was studied for an acid \\ sulfite pulp mill that produces dissolving pulps. Laboratory analyses of the \\ last two bleaching stages, an oxidant-reinforced alkaline extraction stage \\ (EOP), and a subsequent pressurized peroxide with oxygen stage (PO), \\ were performed on a eucalypt pulp that had been delignified by an ozone \\ (Z) stage in the pulp mill. The goal was to predict the optimal costs and \\ operational conditions for the (EOP)(PO) partial bleach sequence for three \\ different specialty pulp products. Four independent variables affecting the \\ pulp quality properties were examined for each stage (i.e., reaction \\ temperature, reaction time, $\mathrm{NaOH}$ dosage and $\mathrm{H}_{2} \mathrm{O}_{2}$ dosage). The \\ dependent variables were various pulp properties, such as intrinsic pulp \\ viscosity, alpha-cellulose content, kappa number, and GE brightness. \\ Three scenarios were considered to optimize the bleaching process, which \\ related to a regenerated cellulose product (viscose) that is widely \\ commercialized, and to two novel products (nanocrystalline cellulose \\ (NCC) and nanofibrillated cellulose (NFC). Statistical response surface \\ models indicated that the bleaching behavior of the ozone-treated pulp \\ could be represented by second-order polynomial equations. These non- \\ linear optimization models predict cost savings of $62.2 \%, 73.4 \%$, and \\ $63.3 \%$ for producing viscose, NCC, and NFC pulp grades, respectively.
}

Keywords: Sulfite pulping; Dissolving pulp; Alkaline extraction; Peroxide bleaching; Regenerated cellulose

Contact information: a: Department of Chemistry and Process \& Resources Engineering. Green Engineering and Resources Group, GER (www.geruc.es). University of Cantabria, 39005 Santander, Spain;

b: Department of Bioproducts and Biosystems, School of Chemical Engineering, Aalto University. 00076 Aalto, Espoo, Finland; *Corresponding author: alberto.coz@unican.es

\section{INTRODUCTION}

Dissolving pulp is the raw material for the production of a wide range of cellulose derivatives, such as viscose staple fibers, cellulose esters, and ethers (Kumar and Christopher 2017). Dissolving pulp contains high levels of cellulose (90 to 98\%) and exhibits very high brightness values (>90 \% ISO) (Liu et al. 2016); consequently, these pulps have high-cellulose purity in comparison with mechanical, thermomechanical, semichemical, or some chemical pulps. Some processes that are being investigated to produce dissolving pulp are the $\mathrm{SO}_{2}$-ethanol-water (SEW) process (Iakovlev et al. 2011; Yahamoto et al. 2014) or the direct purification of paper-grade pulp (Roselli et al. 2014; Duan et al. 2017). Other well-known processes already manufacture dissolving pulps, such as prehydrolysis kraft (PHK) (Duan et al. 2015; Matin et al. 2015; Chen et al. 2016), prehydrolysis soda-anthraquinone (SAQ) (Sixta and Schild 2009) and acid sulfite (AS) (Llano et al. 2012; Llano et al. 2015).

Dissolving pulp demands have been growing worldwide during the last decade, especially in China. Sixta et al. (2013) described that the upturn of wood pulp in the market 
during the last 10 years might be attributed to a consistent growth for the regenerated cellulose fiber market. The recent outlook for the global dissolving pulp market published by RISI (2016) shows a demand increasing from 3.1 Mton/year in 2000 to $7.3 \mathrm{Mton} / \mathrm{year}$ in 2016; this outlook report estimates that this market will keep growing in subsequent years. This observation has evoked a huge interest in not only the pulping sector, but also in the textile and paper sectors; consequently, researchers worldwide are investigating this topic.

Bleaching is a crucial step in the manufacturing of dissolving pulps, whereby trace amounts of lignin, hemicelluloses, and other impurities are eliminated that are not removed during the chemical pulping process. More specifically, bleaching aims to increase pulp brightness and purity, while adjusting the cellulose's viscosity and molecular weight distribution. Hence, bleaching accomplishes the following objectives: (i) to modify the reactivity of the cellulose in the resulting dissolving pulp; (ii) to meet customer requirements that utilize the dissolving pulp; and (iii) to increase brightness and purity of the dissolving pulp (Liu et al. 2016; Chen et al. 2016). There are numerous bleaching sequences employed to improve pulp reactivity and adjust pulp viscosity, such as chlorinebased bleaching (Gangwar et al. 2016), elemental chlorine free (ECF) (Bodhlyera et al. 2015; Li et al. 2015; Yao et al. 2016), catalytic bleaching (Kumar Chenna et al. 2016; Afsahi et al. 2018); total chlorine free (TCF) (Li et al. 2015; Zhou 2015; Veisi and Mahdavi 2016), and bio-bleaching with enzymes, such as cellulases (Duan et al. 2017; Hutterer et al. 2017), endoglucanase (Quintana et al. 2015a), xylanase (Hutterer et al. 2017; Zhao et al. 2017), or laccase (García-Fuentevilla et al. 2015; Quintana et al. 2015b).

The research presented in this paper examines the last two stages of an industrial three-stage TCF bleach plant. The unbleached acid sulfite pulp enters the bleach plant and is further delignified by an ozone stage $(Z)$; this stage was not considered in this study since the stage has a very short reaction time and the conditions of the stage is currently being optimized. The options studied following the $\mathrm{Z}$ stage was the oxidant-reinforced alkaline extraction (EOP), and the subsequent pressurized peroxide stage with oxygen (PO). These stages were investigated to see how they affected the physico-chemical properties of the resulting dissolving pulp prior to their conversion into viscose or nanocellulose pulp grades. In a previous publication (Llano et al. 2015), the entire $\mathrm{Z}(\mathrm{EOP})(\mathrm{PO})$ bleach sequence for the acid sulfite mill located in northern Spain was analyzed in general for viscose production. The authors concluded that the bleaching process could be improved to avoid molecular weight degradation of the cellulose. In this study, the (EOP) and (PO) stages will be evaluated to optimize the bleaching conditions to produce the three different dissolving pulp grade products. As was pointed out earlier, the scientific literature contains reports of chlorine-based, ECF, TCF or bio-bleaching sequences that accomplish different objectives. However, the literature does not address how to improve pulp quality when using TCF bleaching sequences to produce high alpha-cellulose dissolving pulp grades that are used for rayon (i.e., man-made regenerated fibers), or for nanocrystalline cellulose (NCC) and nanofibrillated cellulose (NFC).

The viscose was selected for study because of their large proportion in the global market. Liu et al. (2016) remarked that viscose (63\% market share) is the most common product made from dissolving pulp.

Dissolving pulp grades that can be used for producing novel nanocelluloses, such as NFC and NCC, were also selected for study, as these are emerging new materials in the bio-based economy for pulp mills (García et al. 2016). Nanocellulose materials are becoming popular due to their feestocks and renewability; non-abrasive properties; high 
specific strength; and safer handling (Balea et al. 2016). This research will optimize the $(\mathrm{EOP})(\mathrm{PO})$ partial bleach sequence in order to produce viscose grade as the mill currently produces, and also NFC and NCC grades. Hence, this will allow the acid sulfite pulp mill to diversify its business. Models developed from this work will permit the mill to use them as a predictive tool to assess the cost of producing cellulose derivatives without performing a comprehensive laboratory study.

Consequently, the objective of this research was to determine the optimal conditions for the (EOP)(PO) partial bleach sequence in relation to pulp grade specifications: alpha-cellulose content, intrinsic pulp viscosity, kappa number, and pulp brightness. In the first step of this study, a factorial design was performed. Then, mathematical modelling and optimizing of the (EOP)(PO) partial sequence was done by analyzing the effects of the main operational variables on pulp specifications. Bleaching optimization considered three scenarios for the production of different end-cellulose products: a regenerated cellulose product (rayon) and two novel nanocelluose products (CNF and NCC grades). Secondly, the empirical model was validated using a second set of experiment data, which tested intermediate operational conditions that were within the experimental space of the first step. Finally, techno-economic analyses were performed in order optimize the bleaching process to produce each of the three pulp grades with regards to economic parameters of chemical and energy costs. General Algebraic Modeling System (GAMS) software (GAMS Software GmbH, Frechen, Germany) was used to obtain the most cost-effective solution.

\section{EXPERIMENTAL}

Two sets of experiments were carried out for (EOP) and (PO) bleaching stages. First, a factorial experimental design was conducted that covered the combination of the four selected independent variables for each stage. Second, experiments were conducted that modified one of the four independent variables while keeping the remaining variables constant within the experimental space of the initial factorial design. Such is the aforementioned second set of experiments. They were useful for making the validation of the mathematical modelling. Conditions tested with the second round of experiments for the (EOP) stage were: 5, 10, 20, 30, 40, and 60 sodium hydroxide $(\mathrm{NaOH})$ dosage expressed as kg/air-dried tonne (ADT); reaction times of 15, 30, 60, 90, 120 and $180 \mathrm{~min}$; reaction temperatures of $80,90,120,130$ and $140{ }^{\circ} \mathrm{C}$; and hydrogen peroxide $\left(\mathrm{H}_{2} \mathrm{O}_{2}\right)$ dosages of $0,5,10,15,20$ and $40 \mathrm{~kg} / \mathrm{ADT}$. In the case of (PO) stage, the conditions tested were: 5, 10, 30, 40 and $60 \mathrm{NaOH}$ dosage expressed as $\mathrm{kg} / \mathrm{ADT}$; reaction times of 30,60, $90,120,150$ and $180 \mathrm{~min}$; reaction temperatures of $80,100,110,120,130$ and $140{ }^{\circ} \mathrm{C}$; and $\mathrm{H}_{2} \mathrm{O}_{2}$ dosages of 5, 10, 20, 30, 40 and $60 \mathrm{~kg} / \mathrm{ADT}$.

\section{Bleaching Procedure}

Laboratory (EOP) and (PO) bleaching tests were conducted in $1 \mathrm{~L}$ stainless-steel reaction vessels. For the (EOP) stage, sodium hydroxide acts as the solubilizing agent for extracting modified lignin fragments together with oxygen and hydrogen peroxide, which further oxidizes and fragments the residual lignin. The (PO) stage uses hydrogen peroxide as the brightening agent in the presence of sodium hydroxide and oxygen.

The pulp used in these experiments was washed until resultant filtrate reached the $\mathrm{pH}$ of the tap water used to wash the pulp. Afterwards, the washed pulp was kept at $4{ }^{\circ} \mathrm{C}$ 
to avoid carbohydrate degradation during storage (Yaqoob et al. 2010). Pulp (300 g) was mixed with $\mathrm{H}_{2} \mathrm{O}_{2}$ and $\mathrm{NaOH}$ with the amount of each reagent being dependent upon the statistical experimental design. Hot water $\left(65\right.$ to $\left.70{ }^{\circ} \mathrm{C}\right)$ was added to achieve a pulp consistency value of $11 \%$. The pulp was then introduced to the reactor, and the reactor was sealed and pressurized with oxygen at 1.65 bar for the (EOP) stage and 2.5 bar for the (PO) stage. The oxygen acting as delignifying agent was treated as a constant parameter and is not studied within this research. When the prescribed reaction time had expired, the reactor was depressurized and discharged; the resulting pulp was washed and laboratory handsheets were prepared prior to analyzing pulp properties.

\section{Pulp Analysis}

Pulp handsheets were prepared after pulp washing. Samples taken after (EOP) or (PO) treatment were disintegrated in a rotary stirrer to evenly disperse the pulp in water, filtered with a Büchner funnel and oven dried at $105^{\circ} \mathrm{C}$. Afterwards, pulp handsheets were left to get moisture equilibrium in the air atmosphere.

Intrinsic pulp viscosity was measured in accordance to the ISO 5351 (2010) test standard. The oven-dried pulp $(0.2500 \pm 0.0005 \mathrm{~g})$ was dispersed in $25 \mathrm{~mL}$ of distilled/ deionized water, $25 \mathrm{~mL} 1.0 \mathrm{M}$ curpiethylendiamine solution mixed with the dispersion, and the pulp was mixed until it was fully dissolved. The resulting solution was placed into a Cannon-Fenske 150 viscometer, which was placed into a $25^{\circ} \mathrm{C}$ water bath. The efflux time of the solution to pass through the viscometer was measured. The intrinsic pulp viscosity value was calculated according to the test method procedure.

The amount of alpha-cellulose was determined in accordance to TAPPI T203 cm99 (1999). An oven-dried pulp sample $(0.5 \pm 0.1 \mathrm{~g})$ was extracted with a $17.5 \% \mathrm{NaOH}$ solution at $25 \pm 0.2^{\circ} \mathrm{C}$. A $25 \mathrm{~mL}$ portion of the resulting filtrate was taken and mixed with $10 \mathrm{~mL}$ of $0.5 \mathrm{~N} \mathrm{~K}_{2} \mathrm{Cr}_{2} \mathrm{O}_{7}$ and $50 \mathrm{~mL}$ of $96 \% \mathrm{H}_{2} \mathrm{SO}_{4}$. After $15 \mathrm{~min}$, samples were cooled by adding $50 \mathrm{~mL}$ of water, which was then titrated with $0.1 \mathrm{~N}\left(\mathrm{NH}_{4}\right)_{2} \mathrm{Fe}\left(\mathrm{SO}_{4}\right)_{2} \cdot 6 \mathrm{H}_{2} \mathrm{O}$ using ferroin as the end-point indicator.

Kappa number test estimates the amount of residual lignin and hexenuronic acid by measuring the oxidant demand of the pulp. TAPPI Useful Method UM 246 (1991) was used to estimate the kappa number. TAPPI Useful Method UM 246 is known as the micro kappa number test and is used for high-purity pulps, such as partially and fully bleached pulps with high cellulose content and kappa numbers below 5 .

Brightness represents the numerical value of the reflectance factor of a sample with respect to blue light of specific spectral and geometric characteristics. The method is described in the TAPPI Test Method T452 om-08 (2008), and is known as GE (or TAPPI) brightness. The equipment required consist of a reflectometer employing $45^{\circ}$ illumination and $0^{\circ}$ viewing geometry $\left(45^{\circ} / 0^{\circ}\right)$ using light with an effective wavelength of $457 \pm 0.5 \mathrm{~nm}$.

\section{Experimental Design}

The independent variables of reaction time, reaction temperature, $\mathrm{NaOH}$ dosage, and $\mathrm{H}_{2} \mathrm{O}_{2}$ dosage for each stage were modulated in accordance to a statistically-designed three-level, four-factor factorial experimental design. The independent variables were evaluated at three levels: low (-1), medium (0) and high (+1). Ranges of values for the independent variables used in the experimental design at each stage of the (EOP)(PO) partial sequence are shown in Table 1 . The independent variables were normalized (or converted to coded units) from -1 to +1 in order to facilitate direct comparison of the 
coefficients and visualization of the effects of the individual independent variables on the response variable (Eq. 1),

$$
x_{n}=\frac{(x-\bar{x})}{\left(x_{\max }-x_{\min }\right)}
$$

where $x_{n}$ is the coded value of independent variable $n, x$ is the variable's uncoded value, $\bar{x}$ is the average value of the variable, $x_{\max }$ is the maximum value of the variable, and $x_{\min }$ is the minimum value of the variable. Normalization of the independent variables reduces interrelationships between linear and quadratic terms in the developed response surface model (Montgomery 1997).

Experimental errors were calculated from the central points of the statistical experimental design (i.e., first set of experiments) for the (EOP) and (PO) stages. In all cases, the experimental errors were lower than: 10\% for the kappa number; $1 \%$ for the alpha-cellulose content; $5 \%$ for the GE brightness; and 5\% for the intrinsic pulp viscosity.

Table 1. Ranges of the Independent Variables Used in the Experimental Design at (EOP) and (PO) Stages

\begin{tabular}{|c|c|c|c|}
\hline Normalized Value of the (EOP) stage & $\mathbf{- 1}$ & $\mathbf{0}$ & $\mathbf{1}$ \\
\hline $\mathrm{NaOH}(\mathrm{kg} / \mathrm{ADT})$ & 20 & 40 & 60 \\
\hline $\mathrm{H}_{2} \mathrm{O}_{2}(\mathrm{~kg} / \mathrm{ADT})$ & 0 & 20 & 40 \\
\hline Time (min) & 60 & 120 & 180 \\
\hline Temperature ( $\left.{ }^{\circ} \mathrm{C}\right)$ & 90 & 115 & 140 \\
\hline Normalized Value of the (PO) stage & $-\mathbf{1}$ & $\mathbf{0}$ & $\mathbf{1}$ \\
\hline $\mathrm{NaOH}(\mathrm{kg} / \mathrm{ADT})$ & 0 & 30 & 60 \\
\hline $\mathrm{H}_{2} \mathrm{O}_{2}(\mathrm{~kg} / \mathrm{ADT})$ & 20 & 40 & 60 \\
\hline Time (min) & 60 & 120 & 180 \\
\hline Temperature $\left.{ }^{\circ} \mathrm{C}\right)$ & 80 & 110 & 140 \\
\hline
\end{tabular}

The total number of experiments carried out for each stage in the statistical design are illustrated in Fig. 1. The number of experiments ran are calculated by considering: the number of variables $(k)$, which is equal to 4 ; a constant $p$ that is equal to zero at $k<5$ and to 1 at $k>5$; and the number of central points $\left(n_{c}\right)$, which is equal to 1 . Hence, the number of experiments for $2^{k-p}$ factor design points, $2 \cdot k$ star points and $n_{c}$ central points is calculated as (Eq. 2):

$$
n=2^{(k-p)}+2 \cdot k+n_{c}=2^{(4-0)}+2 \cdot 4+1=25
$$

There are 16 factor design experiments, eight star point experiments and one central point, which yielded a total of 25 experiments for each stage (50 experiments total).

Apart from the above experimental design, additional laboratory bleaching experiments of (EOP) and (PO) stages were conducted by modifying one of the independent variables while keeping the remaining variables constant. Such is the aforementioned second set of experiments. These experiments were used to validate the second-order response surface model derived from the earlier statistical design-ofexperiments for each bleaching stage. 

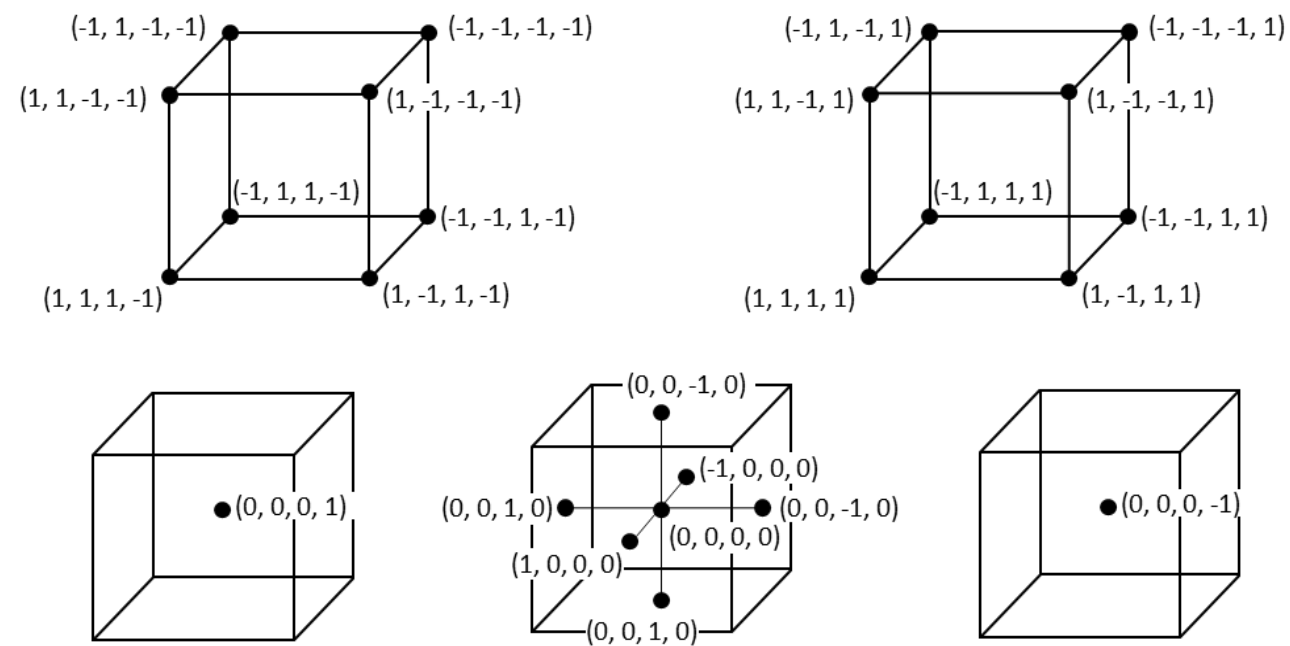

Fig. 1. Plot of the coordinates for the experiments included in the experimental design that are based on four independent variables for each bleaching stage

ANOVA analysis was done to obtain the coefficients that were included in the GAMS software and to obtain statistics such as $\mathrm{R}^{2}$, standard error, and F-value. Pareto charts were constructed to graphically determine the most important effects with a statistical confidence level of $95 \%$ and their impact over the quality pulp parameters. Response surface graphs were plotted since they present useful information about the behavior of a response variable in the whole studied range. Additionally, the Parity plots reveal how mathematical models are useful in the factorial experimental design and also in other conditions inside the system boundaries.

\section{Mathematical Modelling}

The statistical design-of-experiments enabled the construction of the second-order response surface model, and the detection of statistical significance with the variables examined. The dependent variable responses were predicted using the second-order response surface model of the form,

$$
y_{k}=a_{0}+\sum_{i=1}^{n}\left(b_{i} x_{i}\right)+\sum_{i=1}^{n}\left(c_{i} x_{i}^{2}\right)+\sum_{i<} \sum_{j}\left(d_{i j} x_{i} x_{j}\right)
$$

where $x_{i}$ are the independent variables (uncoded values); $y_{k}$ dependent variables; $n$ the number of independent variables $(n=4)$; and $k$ is the number of dependent variables $(k=4)$. The terms $b_{i}, c_{i}$ and $d_{i j}$ denote coefficient terms for linear, quadratic, and binary interaction terms of the independent variables; the $a_{0}$ term denotes the intercept value for dependent variable $y_{k}$. All terms of the models with statistical $p$-values higher than 0.05 were not included, which represented a statistical confidence level of 95\%. The coefficients and factors for the response surface models were determined from the analysis of the experimental data using Statgraphics statistical software (Statpoint Technologies, Inc, The Plains, VA, USA).

\section{Optimization}

The mathematical model developed from the statistical design-of-experiments was used for the optimization of the bleaching process with the GAMS software. Optimization 
considered the key pulp specifications. Not all end-cellulose products have the same pulp specifications; hence, three different models were developed for optimum bleaching for producing: (i) viscose; (ii) nanocrystalline cellulose; and (iii) nanofibrillated cellulose grades.The general objective function $(Z)$ for the three scenarios is the same and consists of minimizing the expression (Eq. 4):

$$
Z=\sum \operatorname{costs}_{\text {energy }}+\sum \operatorname{costs}_{\text {chemicals }}
$$

Costs related to energy (costs energy $_{\text {}}$ ) and chemical (costs chemical $_{\text {ch }}$ consumption for each stage were considered since they are the major contributors to bleaching costs. Energy costs for (EOP) and (PO) stages were calculated by Eqs. 5 and 6, respectively:

$$
\begin{aligned}
& \operatorname{Cost}_{\mathrm{energy}}^{\mathrm{EOP}}(€)=7.16\left(\frac{\mathrm{ODT}}{\mathrm{h}}\right) \cdot \frac{1}{0.9}\left(\frac{\mathrm{ADT}}{\mathrm{ODT}}\right) \cdot \frac{1}{3600}\left(\frac{\mathrm{h}}{\mathrm{s}}\right) \\
& \cdot 1.55 \cdot\left(\frac{\mathrm{kW} \cdot \mathrm{s}}{\mathrm{AD} \mathrm{kg} \cdot{ }^{\circ} \mathrm{C}}\right) \cdot 0.083\left(\frac{€}{\mathrm{~kW} \cdot \mathrm{h}}\right) \cdot \frac{1}{60}\left(\frac{\mathrm{h}}{\mathrm{min}}\right) \cdot \frac{1000}{1}\left(\frac{\mathrm{AD} \mathrm{kg}}{\mathrm{ADT}}\right) \\
& \cdot t_{\mathrm{R}}^{\mathrm{EOP}}(\mathrm{min}) \cdot\left(T^{\mathrm{EOP}}-65\right)\left({ }^{\circ} \mathrm{C}\right)=0.00491 \cdot t_{\mathrm{R}}^{\mathrm{EOP}} \cdot\left(T^{\mathrm{EOP}}-65\right) \\
& \operatorname{Cost}_{\mathrm{energy}}^{\mathrm{PO}}(€)=6.3\left(\frac{\mathrm{ODT}}{\mathrm{h}}\right) \cdot \frac{1}{0.9}\left(\frac{\mathrm{ADT}}{\mathrm{ODT}}\right) \cdot \frac{1}{3600}\left(\frac{\mathrm{h}}{\mathrm{s}}\right) \\
& \cdot 1.55 \cdot\left(\frac{\mathrm{kW} \cdot \mathrm{s}}{\mathrm{AD} \mathrm{kg} \cdot{ }^{\circ} \mathrm{C}}\right) \cdot 0.083\left(\frac{€}{\mathrm{~kW} \cdot \mathrm{h}}\right) \cdot \frac{1}{60}\left(\frac{\mathrm{h}}{\mathrm{min}}\right) \cdot \frac{1000}{1}\left(\frac{\mathrm{AD} \mathrm{kg}}{\mathrm{ADT}}\right) \\
& \cdot t_{\mathrm{R}}^{\mathrm{PO}}(\mathrm{min}) \cdot\left(T^{\mathrm{PO}}-65\right)\left({ }^{\circ} \mathrm{C}\right)=0.00432 \cdot t_{\mathrm{R}}^{\mathrm{PO}} \cdot\left(T^{\mathrm{PO}}-65\right)
\end{aligned}
$$

Individual chemical costs for the (EOP) stage ((Eqs. 7, 8, and 9) and the (PO) stage (Eqs. 10,11 and 12) were calculated. For the chemical costs they were considered consumptions of $\mathrm{NaOH}, \mathrm{H}_{2} \mathrm{O}_{2}$ (process variables studied in this work) and oxygen (considered as a constant in this work) but also consumed during the bleaching sequence.

$$
\begin{aligned}
& \operatorname{Cost}_{\mathrm{NaOH}}^{\mathrm{EOP}}(€)=7.16\left(\frac{\mathrm{ODT}}{\mathrm{h}}\right) \cdot \frac{1}{0.9}\left(\frac{\mathrm{ADT}}{\mathrm{ODT}}\right) \cdot \frac{1}{60}\left(\frac{\mathrm{h}}{\mathrm{min}}\right) \\
& \cdot 0.195\left(\frac{€ \mathrm{NaOH}}{\mathrm{kg} \mathrm{NaOH}}\right) \cdot C_{\mathrm{NaOH}}^{\mathrm{EOP}}\left(\frac{\mathrm{kg} \mathrm{NaOH}}{\mathrm{AdT}}\right) \cdot t_{\mathrm{R}}^{\mathrm{EOP}}(\mathrm{min}) \\
& =0.0259 \cdot C_{\mathrm{NaOH}}^{\mathrm{EOP}} \cdot t_{\mathrm{R}}^{\mathrm{EOP}} \\
& \operatorname{Cost}_{\mathrm{H}_{2} \mathrm{O}_{2}}^{\mathrm{EOP}}(€)=7.16\left(\frac{\mathrm{ODT}}{\mathrm{h}}\right) \cdot \frac{1}{0.9}\left(\frac{\mathrm{ADT}}{\mathrm{ODT}}\right) \cdot \frac{1}{60}\left(\frac{\mathrm{h}}{\mathrm{min}}\right) \\
& \cdot 0.560\left(\frac{€ \mathrm{H}_{2} \mathrm{O}_{2}}{\mathrm{~kg} \mathrm{H} \mathrm{H}_{2} \mathrm{O}_{2}}\right) \cdot C_{\mathrm{H}_{2} \mathrm{O}_{2}}^{\mathrm{EOP}}\left(\frac{\mathrm{kg} \mathrm{H} \mathrm{O}_{2}}{\mathrm{ADT}}\right) \cdot t_{\mathrm{R}}^{\mathrm{EOP}}(\mathrm{min}) \\
& =0.0743 \cdot C_{\mathrm{H}_{2} \mathrm{O}_{2}}^{\mathrm{EOP}} \cdot t_{\mathrm{R}}^{\mathrm{EOP}} \\
& \operatorname{Cost}_{\mathrm{O}_{2}}^{\mathrm{EOP}}(€)=7.16\left(\frac{\mathrm{ODT}}{\mathrm{h}}\right) \cdot \frac{1}{0.9}\left(\frac{\mathrm{ADT}}{\mathrm{ODT}}\right) \cdot \frac{1}{60}\left(\frac{\mathrm{h}}{\mathrm{min}}\right) \\
& \cdot 3\left(\frac{\mathrm{kg} \mathrm{O} \mathrm{O}_{2}}{\mathrm{ADT}}\right) \cdot t_{\mathrm{R}}^{\mathrm{EOP}}(\mathrm{min})=0.025\left(\frac{€ \mathrm{O}_{2}}{\mathrm{~kg} \mathrm{O} \mathrm{O}_{2}}\right)
\end{aligned}
$$




$$
\begin{aligned}
& \operatorname{Cost}_{\mathrm{NaOH}}^{\mathrm{PO}}(€)=6.3\left(\frac{\mathrm{ODT}}{\mathrm{h}}\right) \cdot \frac{1}{0.9}\left(\frac{\mathrm{ADT}}{\mathrm{ODT}}\right) \cdot \frac{1}{60}\left(\frac{\mathrm{h}}{\mathrm{min}}\right) \\
& \cdot 0.195\left(\frac{€ \mathrm{NaOH}}{\mathrm{kg} \mathrm{NaOH}}\right) \cdot C_{\mathrm{NaOH}}^{\mathrm{PO}}\left(\frac{\mathrm{kg} \mathrm{NaOH}}{\mathrm{ADT}}\right) \cdot t_{\mathrm{R}}^{\mathrm{PO}}(\mathrm{min}) \\
& =0.0228 \cdot C_{\mathrm{NaOH}}^{\mathrm{PO}} \cdot t_{\mathrm{R}}^{\mathrm{PO}} \\
& \operatorname{Cost}_{\mathrm{H}_{2} \mathrm{O}_{2}}^{\mathrm{PO}}(€)=6.3\left(\frac{\mathrm{ODT}}{\mathrm{h}}\right) \cdot \frac{1}{0.9}\left(\frac{\mathrm{ADT}}{\mathrm{ODT}}\right) \cdot \frac{1}{60}\left(\frac{\mathrm{h}}{\mathrm{min}}\right) \cdot 0.560\left(\frac{€ \mathrm{H}_{2} \mathrm{O}_{2}}{\mathrm{~kg} \mathrm{H}_{2} \mathrm{O}_{2}}\right) \\
& \cdot C_{\mathrm{H}_{2} \mathrm{O}_{2}}^{\mathrm{PO}}\left(\frac{\mathrm{kg} \mathrm{H} \mathrm{O}_{2}}{\mathrm{ADT}}\right) \cdot t_{\mathrm{R}}^{\mathrm{PO}}(\mathrm{min})=0.0653 \cdot C_{\mathrm{H}_{2} \mathrm{O}_{2}}^{\mathrm{PO}} t_{\mathrm{R}}^{\mathrm{PO}} \\
& \operatorname{Cost}_{\mathrm{O}_{2}}^{\mathrm{PO}}(€)=6.3\left(\frac{\mathrm{ODT}}{\mathrm{h}}\right) \cdot \frac{1}{0.9}\left(\frac{\mathrm{ADT}}{\mathrm{ODT}}\right) \cdot \frac{1}{60}\left(\frac{\mathrm{h}}{\mathrm{min}}\right) \cdot 0.065\left(\frac{€ \mathrm{O}_{2}}{\mathrm{~kg} \mathrm{O}_{2}}\right) \\
& \cdot 3\left(\frac{\mathrm{kg} \mathrm{O}}{\mathrm{ADT}}\right) \cdot t_{\mathrm{R}}^{\mathrm{PO}}(\mathrm{min})=0.0228 \cdot t_{\mathrm{R}}^{\mathrm{PO}}
\end{aligned}
$$

Equations 4 to 12 were developed by taking into account data provided by the pulp mill, and considering the mass balances, reagent prices, production, and consumption per Air Dried Tonne (ADT) of dissolving pulp. With regard to the energy cost of 0.083 $€ / \mathrm{KW} \cdot \mathrm{h}$, this data was taken from the Ministry of Commerce Industry and Tourism (MINCOTUR 2018). The only costs considered in the three optimization models were the major contributors to the bleaching costs, which correspond to reagent and energy costs. Water consumption or labour costs were not introduced in the models.

Pulp production rates of oven-dried tonne (ODT) basis were converted to air-dried tonne (ADT) basis assuming a 10\% moisture content. Costs equations (Eqs. 5 to 12) were expressed as functions of the independent variables of $t_{R}^{\mathrm{PO}}, t_{\mathrm{R}}^{\mathrm{EOP}}, \mathrm{C}_{\mathrm{NaOH}}^{\mathrm{PO}}, \mathrm{C}_{\mathrm{NaOH}}^{\mathrm{EOP}}, \mathrm{C}_{\mathrm{H}_{2} \mathrm{O}_{2}}^{\mathrm{PO}}$, $\mathrm{C}_{\mathrm{H}_{2} \mathrm{O}_{2}}^{\mathrm{OOP}}, T^{P O}$, and $T^{E O P}$, which were bleach stage reaction times, sodium hydroxide and peroxide dosages, and reaction temperatures for (PO) and (EOP), respectively. Apart from the costs, equations of the response variables (kappa number, alpha-cellulose content, intrinsic pulp viscosity and pulp brightness) as a function of the operational variables (reaction time, peroxide dosage, sodium hydroxide dosage and reaction temperature) were also introduced in the GAMS software. These equations are presented in the Results and Discussion section (Table 3). The whole system of equations constitutes a non-linear problem (NLP) for optimization.

Bleaching chemical pulps to high brightness requires a multi-stage bleach sequence. The first stage or two of the sequence focuses on removing residual lignin in the pulp and are known as delignification stages. The subsequent stages in the sequence are the brightening stages in which the chromophores in the pulp are eliminated (Sixta et al. 2006). In this study, the optimization of $Z(E O P)(P O)$ focused on the (EOP)(PO) partial sequence, where the models for the (EOP) and (PO) stages were considered together when optimizing for the three different scenarios.

Once the objective function was defined and established with the rest of equations, some restrictions were incorporated to refine the objective function. Such restrictions vary as a function of the pulp grade and are summarized in Table 2. These restrictions should be accomplished at the end of the (EOP)(PO) partial sequence in order to meet the product specifications of the dissolving pulp grade.

Constraints applied to the (EOP) stage are the same for all dissolving pulp grades. (EOP) restrictions were: 89 to $90 \%$ alpha-cellulose content, 70 to $80 \%$ brightness (GE), intrinsic pulp viscosity of 550 to $610 \mathrm{~mL} / \mathrm{g}$, and kappa number of 1.0 to 2.0. In the case of 
the (PO) stage, the product specifications for viscose, NCC and NFC pulp grades were taken from the literature (Abraham et al. 2011; Sehaqui et al. 2011; Tonoli et al. 2012; Wang et al. 2012; Zhao et al. 2013; Barbash et al. 2017a; Barbash et al. 2017b). These (PO) stage constraints for each pulp grade are shown in Table 2.

Table 2. Final Quality Pulp Properties for the Models

\begin{tabular}{|l|c|c|c|}
\cline { 2 - 4 } \multicolumn{1}{c|}{} & (i) Viscose & (ii) NCC & (iii) NFC \\
\hline$\alpha$-Cellulose (\%) & 92 to 94 & 94 to 96 & 92.2 to 96 \\
\hline Brightness $(\% \mathrm{GE})$ & 90 to 92 & 80 & 92 to 94 \\
\hline Intrinsic Viscosity $(\mathrm{mL} / \mathrm{g})$ & 400 to 600 & 250 to 588 & 500 to 600 \\
\hline Kappa No. & 0.2 to 0.5 & 0.5 to 0.6 & $>0.7$ \\
\hline
\end{tabular}

\section{RESULTS AND DISCUSSION}

\section{Raw Material Characterization}

Pulp samples provided by the Sniace S.A. pulp mill (Torrelavega, Spain) were characterized prior to conducting the bleaching experiments. The acid sulfite pulp was made from Eucalyptus globulus. The pulp used for laboratory (EOP) bleaching had undergone an ozone delignification $(\mathrm{Z})$ stage at the mill, and had a kappa number of $2.89 \pm 0.21$, an alpha-cellulose content of $88.9 \pm 0.3 \%$, an intrinsic pulp viscosity of $625 \pm 30$ $\mathrm{mL} / \mathrm{g}$, and a GE brightness of $66.8 \pm 2.5 \%$. The pulp used for laboratory (PO) bleaching had been obtained after the mill's Z(EOP) partial bleach sequence, and had a kappa number of $1.76 \pm 0.11$, alpha-cellulose of $90.9 \pm 0.8 \%$, intrinsic viscosity of $557 \pm 26.2 \mathrm{~mL} / \mathrm{g}$, and a GE brightness of $69.8 \pm 2.0 \%$.

\section{Experimental Design and Mathematical Modelling}

The first set of experiments (Tables 1 and 2) were used to perform a mathematical model capable to predict the response variables as a function of the four independent selected variables within the range of study. Second-order response surface models obtained from the design-of-experiments fitted the data well; the regression coefficients of the statistical surface models and $F$-values are provided in Table 3 . The coefficients of the mathematical adjustment are shown in Table 3. The equation is given by Eq.13.

$$
\begin{aligned}
& \mathrm{y}_{\mathrm{i}}=\mathrm{a}_{1, \mathrm{i}}[\mathrm{NaOH}]+\mathrm{a}_{2, \mathrm{i}} \text { Time }+\mathrm{a}_{3, \mathrm{i}} \text { Temperature }+\mathrm{a}_{4, \mathrm{i}}\left[\mathrm{H}_{2} \mathrm{O}_{2}\right]+\mathrm{a}_{5, \mathrm{i}}[\mathrm{NaOH}]^{2}+\mathrm{a}_{6, \mathrm{i}} \text { Time }^{2}+ \\
& +\mathrm{a}_{7, \mathrm{i}} \text { Temperature }{ }^{2}+\mathrm{a}_{8, \mathrm{i}}\left[\mathrm{H}_{2} \mathrm{O}_{2}\right]^{2}+\mathrm{a}_{9, \mathrm{i}}[\mathrm{NaOH}] \text { Time }+\mathrm{a}_{10, \mathrm{i}}[\mathrm{NaOH}] \mathrm{Temp}+\mathrm{a}_{11, \mathrm{i}}[\mathrm{NaOH}]\left[\mathrm{H}_{2} \mathrm{O}_{2}\right]+ \\
& +\mathrm{a}_{12, \mathrm{i}} \text { Time Temp }+\mathrm{a}_{13, \mathrm{i}} \text { Time }\left[\mathrm{H}_{2} \mathrm{O}_{2}\right]+\mathrm{a}_{14, \mathrm{i}} \text { Temp }\left[\mathrm{H}_{2} \mathrm{O}_{2}\right]+\mathrm{a}_{0, \mathrm{i}}
\end{aligned}
$$

Statistical analyses revealed how well the data fitted with second-order polynomial. These empirical models describe end-quality pulp properties as a function of the operational variables of the $(\mathrm{EOP})$ and $(\mathrm{PO})$ stages (i.e., reaction time, reaction temperature, $\mathrm{NaOH}$ dosage, and $\mathrm{H}_{2} \mathrm{O}_{2}$ dosage). Only significant factors giving a $p$-value less than 0.05 were considered in the final response surface models. Pareto charts (Fig. 3) indicated that the most influential variables affecting the end-quality pulp characteristics. The standardized effect (positive or negative) for each independent variable is also 
represented in the Pareto charts. Three-dimensional graphs of each dependent variable against the two most influential variables are displayed in Fig. 4 for (EOP) and (PO) stages.

Table 3. Coefficients for Each Independent Variable in the Models to Predict Dependent Variables for (EOP) and (PO) Stages with ANOVA Analyses

\begin{tabular}{|c|c|c|c|c|}
\hline \multirow{2}{*}{ EOP Stage Factors (j) } & \multicolumn{4}{|c|}{ Coefficient $\left(a_{\mathrm{j}, \mathrm{i}}\right.$ of Eq. $)$} \\
\hline & Kappa No. & $\alpha$-Cellulose & Intrinsic Viscosity & GE Brightness \\
\hline$[\mathrm{NaOH}]$ & -0.0692 & -0.221 & 0.565 & -0.0578 \\
\hline Time & -0.0179 & -0.0218 & -1.23 & $-8.6410^{-3}$ \\
\hline Temperature & -0.0353 & -0.0692 & 1.89 & -0.0670 \\
\hline$\left[\mathrm{H}_{2} \mathrm{O}_{2}\right]$ & -0.0311 & -0.0303 & -8.02 & 0.426 \\
\hline$[\mathrm{NaOH}]^{2}$ & - & - & - & - \\
\hline Time $^{2}$ & - & - & - & - \\
\hline Temperature $^{2}$ & - & - & -0.0302 & - \\
\hline$\left[\mathrm{H}_{2} \mathrm{O}_{2}\right]^{2}$ & $8.3610^{-4}$ & $2.0810^{-3}$ & 0.128 & -0.0105 \\
\hline$[\mathrm{NaOH}] \cdot$ Time & $1.0710^{-4}$ & - & -0.0628 & - \\
\hline$[\mathrm{NaOH}] \cdot \mathrm{Temp}$ & $4.1410^{-4}$ & $2.4510^{-3}$ & 0.0795 & - \\
\hline$[\mathrm{NaOH}] \cdot\left[\mathrm{H}_{2} \mathrm{O}_{2}\right]$ & - & - & -0.111 & $1.5510^{-3}$ \\
\hline Temp-Time & $1.3210^{-4}$ & $1.4710^{-4}$ & 0.0212 & - \\
\hline$\left[\mathrm{H}_{2} \mathrm{O}_{2}\right]$-Time & $-1.71 \cdot 10^{-4}$ & $-7.6110^{-4}$ & $6.4010^{-3}$ & $-5.0310^{-4}$ \\
\hline$\left[\mathrm{H}_{2} \mathrm{O}_{2}\right] \cdot T e m p$ & - & - & - & $3.6510^{-3}$ \\
\hline Intersection & 6.51 & 98.5 & 639 & 78.7 \\
\hline Statistical Data & - & - & - & - \\
\hline No. experiments & 48 & 48 & 48 & 48 \\
\hline$R^{2}$ & 0.888 & 0.972 & 0.987 & 0.970 \\
\hline $\mathrm{R}$ & 0.943 & 0.986 & 0.993 & 0.985 \\
\hline $\mathrm{R}^{2}$ adjusted & 0.878 & 0.969 & 0.9858 & 0.968 \\
\hline Standard Error & 0.189 & 0.309 & 16.9 & 1.39 \\
\hline F-Value & 350 & $4.4210^{5}$ & $4.7910^{3}$ & $1.5310^{4}$ \\
\hline $\begin{array}{l}\text { Weighted residual sum of } \\
\text { squares }\end{array}$ & 1.35 & 3.73 & $1.0210^{4}$ & 75.7 \\
\hline PO Stage Factors (j) & Kappa No. & $\alpha$-Cellulose & Intrinsic Viscosity & GE Brightness \\
\hline$[\mathrm{NaOH}]$ & 0.0275 & 0.152 & 6.76 & 0.127 \\
\hline Time & $-1.4610^{-3}$ & -0.133 & -3.27 & 0.114 \\
\hline Temperature & -0.0584 & 0.321 & -0.374 & 1.02 \\
\hline$\left[\mathrm{H}_{2} \mathrm{O}_{2}\right]$ & -0.0290 & 0.0446 & -9.32 & 0.180 \\
\hline$[\mathrm{NaOH}]^{2}$ & - & - & - & $-1.4010^{-3}$ \\
\hline Time $^{2}$ & - & - & 0.0111 & $-2.7110^{-4}$ \\
\hline Temperature $^{2}$ & $2.2210^{-4}$ & $-2.2610^{-3}$ & - & $-3.9710^{-3}$ \\
\hline$\left[\mathrm{H}_{2} \mathrm{O}_{2}\right]^{2}$ & - & - & - & - \\
\hline$[\mathrm{NaOH}] \cdot$ Time & $-9.210^{-5}$ & $7.0210^{-4}$ & -0.0319 & - \\
\hline$[\mathrm{NaOH}] \cdot \mathrm{Temp}$ & - & $-2.71 \cdot 10^{-3}$ & -0.0164 & $-1.3710^{-3}$ \\
\hline$[\mathrm{NaOH}] \cdot\left[\mathrm{H}_{2} \mathrm{O}_{2}\right]$ & $3.97 \cdot 10^{-4}$ & - & - & $2.4910^{-3}$ \\
\hline Temp-Time & - & $1.6010^{-3}$ & - & $-8.2910^{-4}$ \\
\hline$\left[\mathrm{H}_{2} \mathrm{O}_{2}\right] \cdot$ Time & - & $-4.710^{-4}$ & 0.0417 & $1.3410^{-3}$ \\
\hline$\left[\mathrm{H}_{2} \mathrm{O}_{2}\right] \cdot$ Temp & $3.8110^{-4}$ & - & - & $-4.8110^{-3}$ \\
\hline Intersection $\left(\mathrm{a}_{0, \mathrm{i}}\right)$ & 4.35 & 78.9 & 793 & 30.6 \\
\hline Statistical Data & - & - & - & - \\
\hline No. experiments & 51 & 48 & 49 & 51 \\
\hline$R^{2}$ & 0.957 & 0.966 & 0.959 & 0.961 \\
\hline $\mathrm{R}$ & 0.978 & 0.983 & 0.979 & 0.980 \\
\hline $\mathrm{R}^{2}$ adjusted & 0.953 & 0.963 & 0.955 & 0.958 \\
\hline Standard Error & 0.0764 & 0.796 & 18.5 & 1.27 \\
\hline F-Value & $1.0210^{3}$ & $4.8710^{5}$ & $3.0910^{3}$ & $1.5110^{4}$ \\
\hline Weighted residual sum of & 0.245 & 24.1 & $1.3710^{4}$ & 61.53 \\
\hline
\end{tabular}




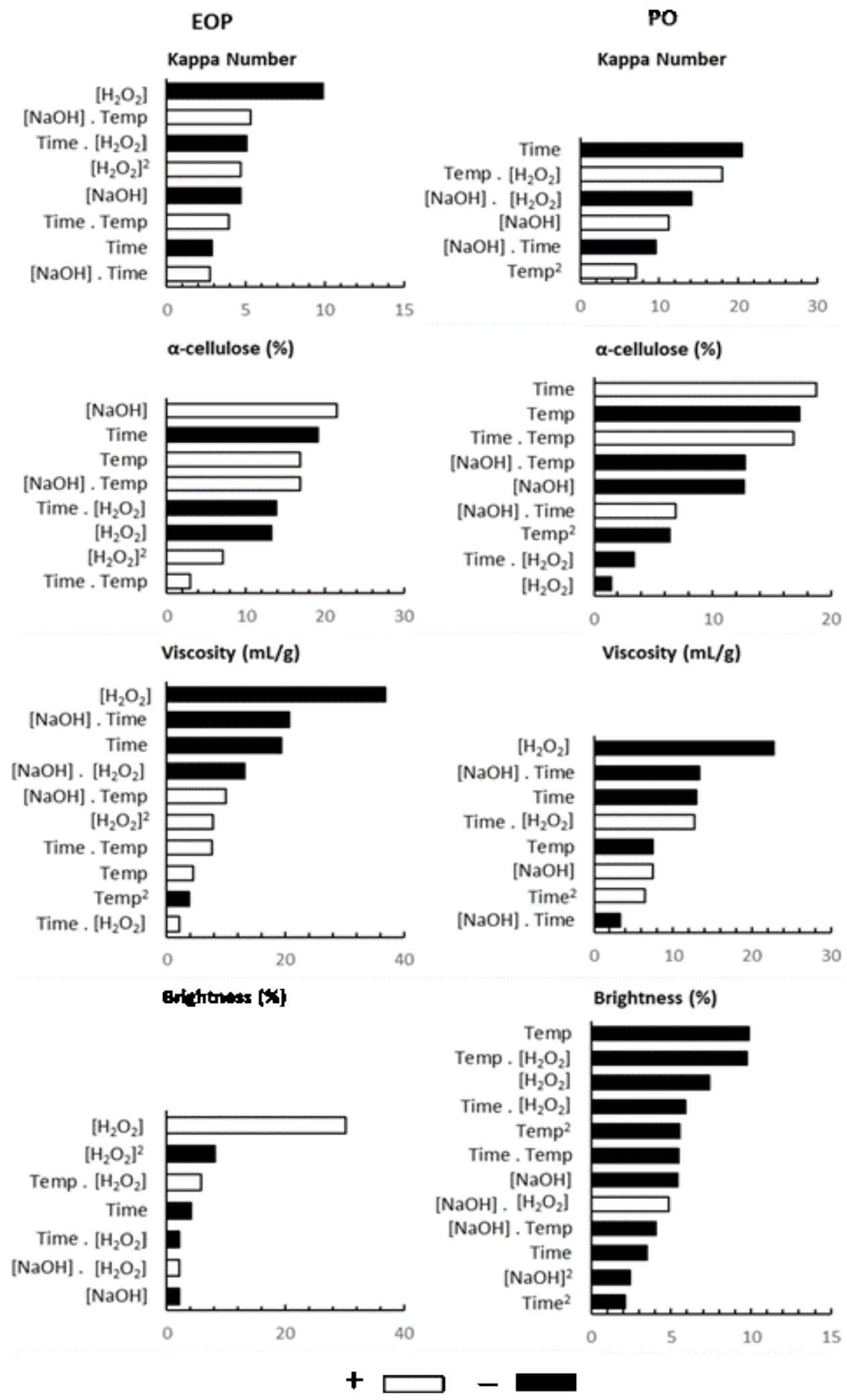

Fig. 3. Pareto charts of standardized effects for (EOP) and (PO) stages 

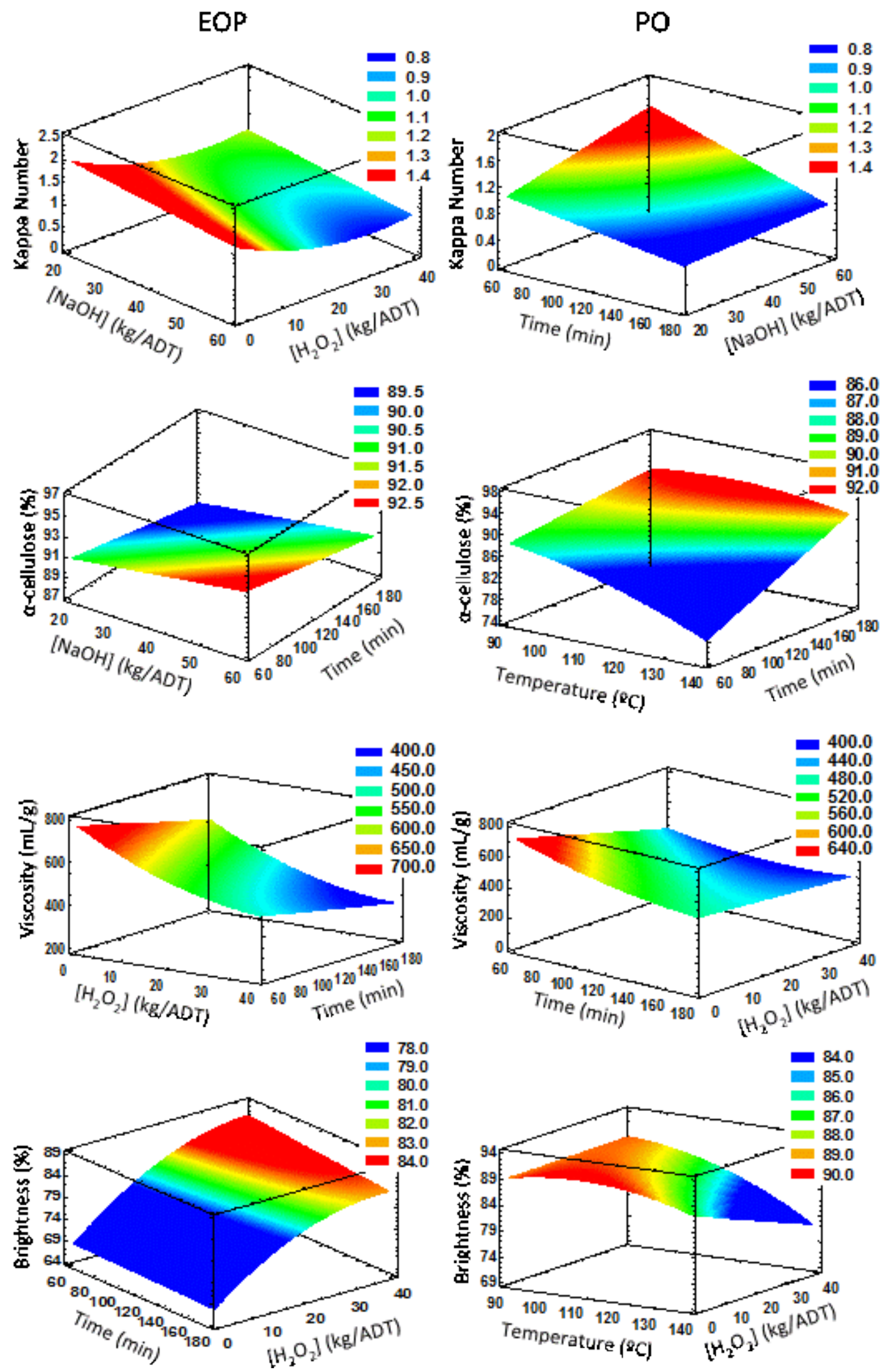

Fig. 4. Response surfaces for kappa number, alpha-cellulose content, intrinsic viscosity and brightness after the (EOP) and the (PO) stage 
The Pareto diagrams showed the standardized effects for linear, quadratic, and binary interaction effects with the four independent variables for the stages. Such diagrams quantify which of the effects have major significance impacts. In general, the linear terms have larger effects on the values of the dependent variables in comparison to the quadratic terms.

Response surface graphs of Fig. 4 made it possible to visualize the optimum operating range under the conditions explored. Such graphs were generated by considering the independent variables that had the greatest cumulative effect $(p<0.05)$ with a statistical confidence level of $95 \%$ for each stage. According to Fig. 3, major effects at (EOP) stage were primarily $\mathrm{H}_{2} \mathrm{O}_{2}$ and $\mathrm{NaOH}$ dosages, except for pulp brightness where $\mathrm{H}_{2} \mathrm{O}_{2}$ dosage and temperature were the variables with the higher impacts. Time and temperature played a more important role for the (PO) stage, except for intrinsic pulp viscosity, which was more influenced by $\mathrm{H}_{2} \mathrm{O}_{2}$ dosage and time.

As can be seen in Fig. 4, optimal operating range conditions are: (i) kappa values below 0.8 in both stages operating with high dosages of $\mathrm{NaOH}$ and $\mathrm{H}_{2} \mathrm{O}_{2}$ in (EOP) and high residence time in (PO); (ii) alpha cellulose content higher than $92 \%$ using high $\mathrm{NaOH}$ dosages and intermediate time (between 60 and $100 \mathrm{~min}$ ) in (EOP) and low temperatures and long residence time in (PO); (iii) for the intrinsic viscosity the normal range of dissolving pulp is represented in the green zone. Such values were reached with $\mathrm{H}_{2} \mathrm{O}_{2}$ dosages from 10 up to $30 \mathrm{~kg} / A D T$ and residence time between 60 and $120 \mathrm{~min}$ for (EOP). The same green zone in (PO) was achieved with low $\mathrm{H}_{2} \mathrm{O}_{2}$ dosages (no more than 10 $\mathrm{Kg} / \mathrm{ADT}$ ) and residence time in the range of 120 to $180 \mathrm{~min}$; (iv) for the brightness the red area is the optimal value giving above $84 \%$ and $90 \%$ GE at (EOP) and (PO) stage.

The results obtained from the experiments of this research are similar to those reported by Matin et al. (2015) for dissolving jute pulp made by the PHK process. The authors noted alpha-cellulose content of 91 to $92 \%$, and GE brightness of 88.3 to $89.5 \%$. Furthermore, Duan et al. (2015) reported that an AS pulp made from eucalypt had an alphacellulose content in the range of 91.34 to $92.90 \%$, and intrinsic pulp viscosities between 498 and $505 \mathrm{~mL} / \mathrm{g}$. Finally, Perrin et al. (2017) indicated that the brightness of a eucalypts PHK pulp bleached with different bleaching sequences ranged between $88.5 \%$ and $89.8 \%$ ISO.

\section{Study of the Operational Variables and Model Validation}

A second set of experiments were conducted by varying one of the independent variables while keeping the others fixed. These results were compared to the earlier experiments of the factorial design (Table 1 and Fig. 1). The second set of experiments studied the influence of one independent variable. In Fig. 5, it was observed that the surface response models fit very well with the experimental data obtained in the second set of experiments. These results confirmed that it is possible to predict which variables affect more to the pulp quality requirements. When examining Fig. 5, it was observed that the following variables have greatest influence: (1) $\mathrm{H}_{2} \mathrm{O}_{2}$ and $\mathrm{NaOH}$ dosages in (EOP), and time and $\mathrm{NaOH}$ dosages in (PO) for the kappa number; (2) time and $\mathrm{NaOH}$ dosage in (EOP), and time and temperature in (PO) for the alpha-cellulose content; and (3) $\mathrm{H}_{2} \mathrm{O}_{2}$ dosage and time for the intrinsic viscosity in both (EOP) and (PO). Figure 5, shows how the equations of the mathematical modelling (continuous black line) fitted well with the experimental data (represented in black and white points for EOP and PO, respectively) considering the small deviation under the tested conditions. 


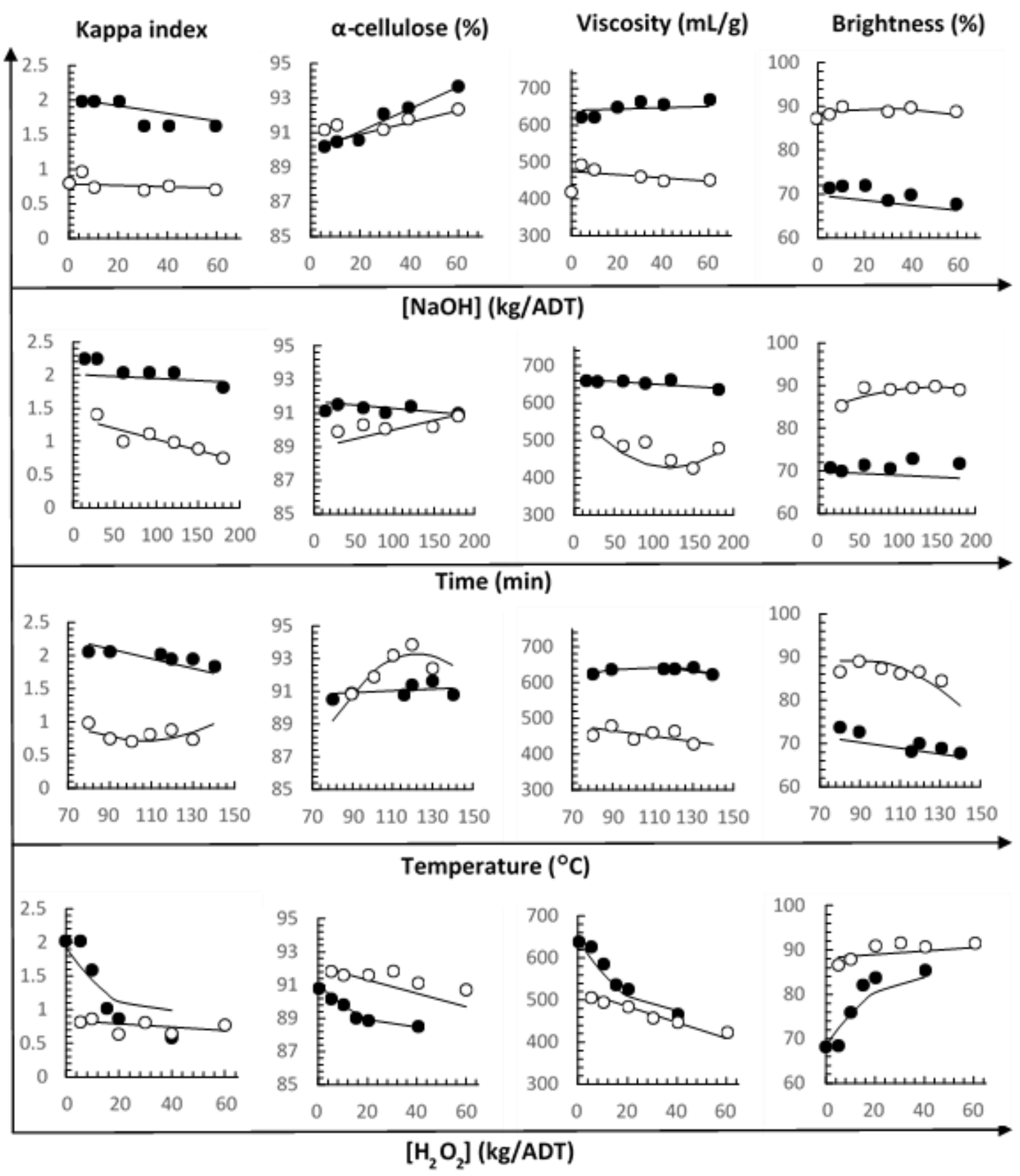

Fig. 5. Comparison of experimental data from the second set of experiments (symbols) to the response surface models (Eq. 3 and Table 3; denoted with lines) for the (EOP) stage (represented by $\bullet$ ) and the (PO) stage (represented by $O$ )

Figure 6 shows the parity plots of the laboratory data from the factorial experiments and the validation experiments to the predictions of the response surface models. It is desirable that the intrinsic viscosity of dissolving pulp be around 400 to $600 \mathrm{~mL} / \mathrm{g}$ (Duan et al. 2015; Chen et al. 2016). This parameter is related to degree of polymerization (DP) of the cellulose. An increase in the intrinsic viscosity during the bleaching stage is thought to be caused by the removal of short-chain carbohydrates, particularly hemicelluloses (Duan et al. 2016). This phenomenon was mostly observed during the (EOP) stage, which solubilizes and extracts oxidized lignin and hemicelluloses. 
A recent study with the $Z(E O P)(P O)$ bleach sequence (Llano et al. 2015) showed an increase of intrinsic pulp viscosity from $560 \mathrm{~mL}$ after the $\mathrm{Z}$ stage to $610 \mathrm{~mL} / \mathrm{g}$ after the (EOP) stage. The study also showed that the hemicelluloses in the AS eucalypt pulp decreased from $5.1 \%$ to $2.2 \%$, and the xylan decreased from $4.5 \%$ to $1.7 \%$ when going through the (EOP) stage.

Looking at Fig. 5, the intrinsic viscosity was barely affected by time, temperature, or $\mathrm{NaOH}$ dosages. Both (EOP) and (PO) were observed to have large intrinsic pulp viscosity losses when the $\mathrm{H}_{2} \mathrm{O}_{2}$ dosage is increased. This is probably due to the degradation of gamma- and beta-cellulose chains by oxidation. A decrease of glucan levels was observed in a previous study (Llano et al. 2015) of the same bleaching sequence from $88.8 \%$ to $87.3 \%$, which was attributed to gamma- and beta-cellulose degradation.

Figure 5 indicated that variables with the most influence over pulp purity were $\mathrm{NaOH}$ and time for the (EOP), and time and temperature for the (PO). In the case with (PO), temperature had the highest impact, resulting in a maximum alpha-cellulose consent of $94 \%$. An alpha-cellulose content of $93.5 \%$ was also reached by adding high amounts of $\mathrm{NaOH}$.

The trends observed for the kappa number, which is related to lignin content, were similar for both (EOP) and (PO) stages. Increasing the reaction time, $\mathrm{NaOH}$ dosage or $\mathrm{H}_{2} \mathrm{O}_{2}$ dosages for either (EOP) or (PO) caused the kappa number to decrease, whereas the reaction temperature had little effect. These observations were hypothesized to be due to the attack of carbonyl groups in the oxidized lignin, which enhanced delignification. Among the selected independent variables, $\mathrm{H}_{2} \mathrm{O}_{2}$ dosages in (EOP) with peroxide loads over $20 \mathrm{Kg} / \mathrm{ADT}$ yielded a kappa number of 0.6 or less, which indicated that hemicelluloses extraction (typically occurring in (EOP)) and lignin extraction are happening at the same time.

Pulp brightness and kappa number are indirectly proportional to one another, whilst the pulp brightness and alpha-cellulose content have the same trend. The (PO) bleaching stage preferably attacks the chromophores of the trace lignin that results in higher pulp brightness. Pulp brightness was always higher after the (PO) versus after the (EOP) regardless bleaching conditions (Fig. 5); GE brightness values after (PO) reached maximum values of 91 to $92 \%$.

As can be seen in the parity plots of Fig. 6, the models fitted well the two experimental data sets with prediction errors being lower than the experimental errors.

Parity plots are useful for the validation of the model at any bleaching time, temperature, $\mathrm{NaOH}$ dosage, and $\mathrm{H}_{2} \mathrm{O}_{2}$ dosage. The models fitted the data well with a global coefficient of determination, $\mathrm{R}^{2}$, of 0.929 and a global $F$-value of $9.61 \cdot 10^{4}$, which indicated that the models explained most of the observed variances. Individual $\mathrm{R}^{2}$ and $F$-value were also calculated and shown in Fig. 6. It was concluded that the proposed models should be able to predict the bleaching behavior of the acid sulfite pulp through (EOP)(PO) partial sequence for the ranges examined. The correlation coefficient, $\mathrm{R}$, were above 0.91 for the pulp property parameters (i.e., 0.99, 0.95, 0.97 and 0.99 for kappa number, alpha-cellulose, intrinsic viscosity and GE brightness, respectively). Furthermore, only a few number of predictions differed from the experimental data with the prediction errors where higher than the experimental errors. 


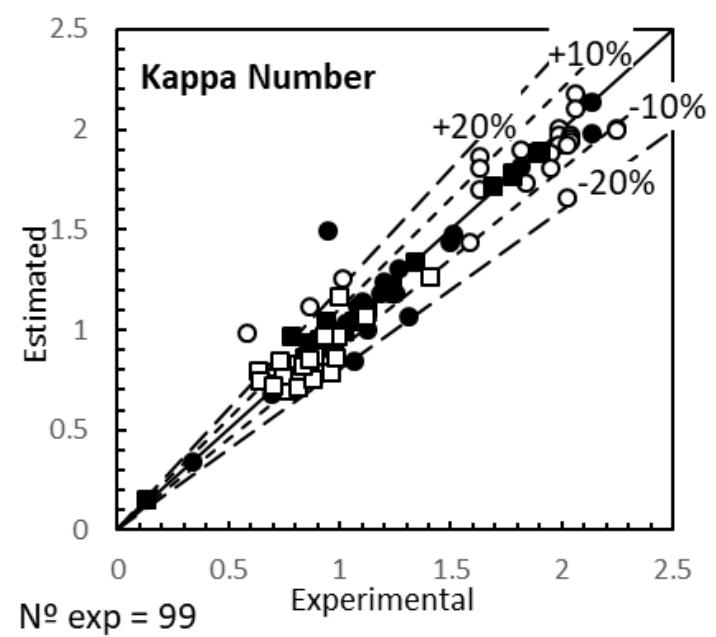

№ $\exp$ with errors $>10 \%=25$

$\mathrm{R}^{2}=0.910$

Standard error of estimate $(E O P)=5.0010^{-2}$

Standard error of estimate $(\mathrm{PO})=1.1710^{-1}$

$\mathrm{F}$-value $=5.4210^{3}$

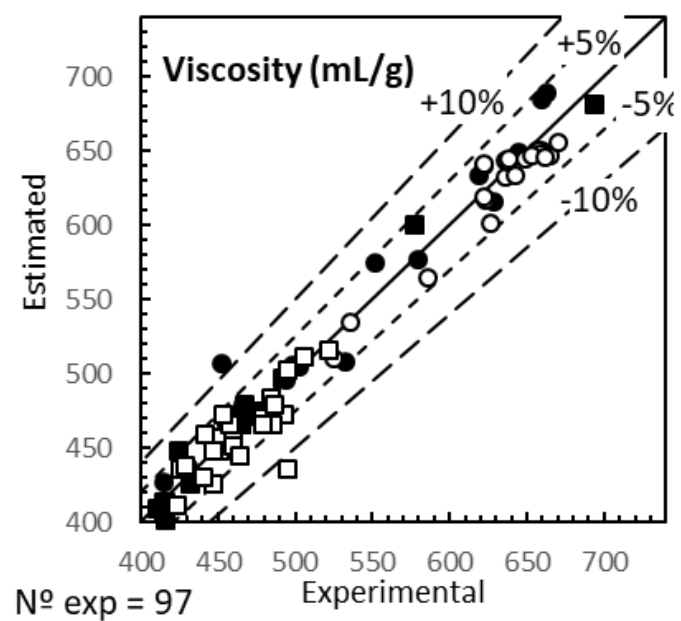

№ $\exp$ with errors $>5 \%=6$

$\mathrm{R}^{2}=0.978$

Standard error of estimate $(E O P)=12.0$

Standard error of estimate $(\mathrm{PO})=10.3$

$\mathrm{F}$-value $=1.0410^{5}$

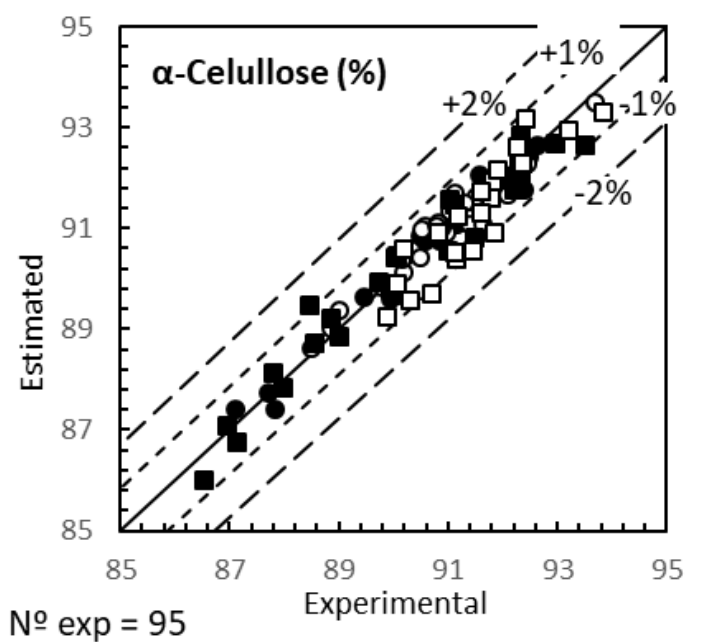

№ $\exp$ with errors $>1 \%=4$

$\mathrm{R}^{2}=0.967$

Standard error of estimate $(E O P)=0.204$

Standard error of estimate $(P O)=0.506$

$\mathrm{F}$-value $=1.3210^{6}$

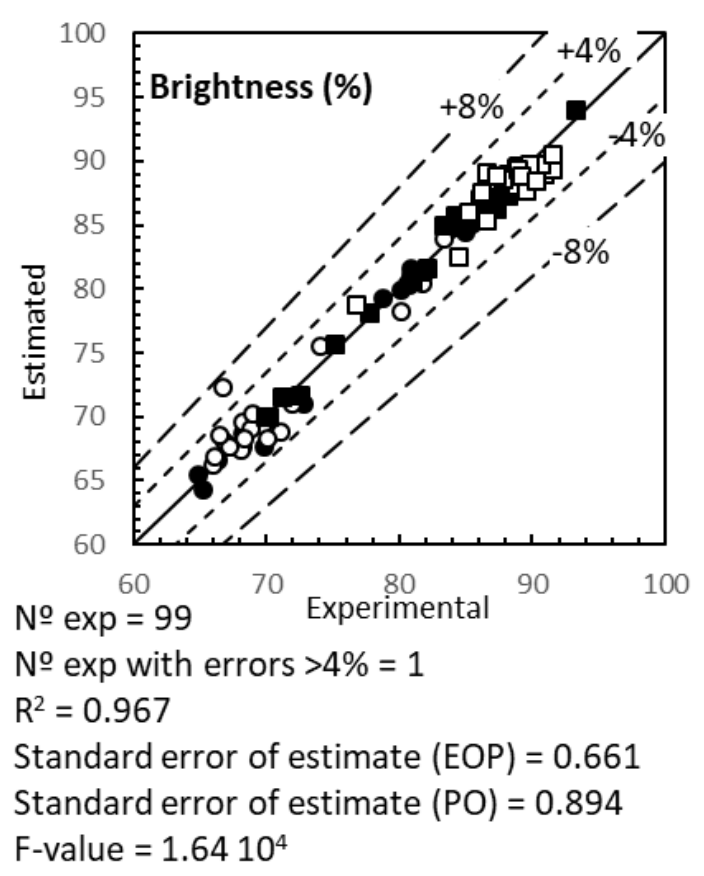

Fig. 6. Parity plots comparing the two experimental data sets with the predictions of the response surface models derived from the factorial design experiments: (EOP) represented by $\bullet$ (factorial design data) and $\mathrm{O}$ (validation data), and (PO) represented by factorial design data) and $\square$ (validation data)

\section{Bleaching Optimization Models}

The key dissolving pulp properties include alpha-cellulose, residual lignin and hemicellulose content, which indicate the purity of the cellulose, and degree of polymerization (DP), which is related to intrinsic pulp viscosity. The main objective in the bleach plant for dissolving pulps is to remove residual lignin and hemicelluloses, and to retain alpha-cellulose within a certain intrinsic viscosity and molecular weight range. 
For a typical rayon grade, the dissolving cellulose has an alpha-cellulose content of 92 to $94 \%$ for the acid sulfite pulping process; the desirable intrinsic viscosity for this grade is 400 to $600 \mathrm{~mL} / \mathrm{g}$ (Duan et al. 2015; Chen et al. 2016). Dissolving pulps with lower alphacellulose levels are predominantly used to manufacture viscose grades, whereas higher alpha-cellulose levels are used for cellulose acetate, cellulose ether, and other specialty product grades (Sixta et al. 2006). Additionally, the presence of excessive amounts of hemicelluloses can have negative effects when the dissolving pulp is converted to rayon (i.e., incomplete xanthation of the cellulose). Brightness should be higher than $90 \%$ ISO for viscose grade (Sixta 2000). In the case of nanocellulose products (NFC and NCC), the dissolving pulp quality parameters are not as strict as those in the cases of rayon. All dissolving pulp quality restrictions for each of the various pulp grades are listed in Table 2. Results of the optimization of the energy and chemical costs associated with (EOP) and (PO) stages obtained for the three pulp grade scenarios are shown in Table 4. As was explained earlier, there is one model used for (EOP) stage for all pulp grades, whereas different (PO) models are used for each pulp grade.

Table 4. Operating Conditions and Optimized Costs for Each End-Cellulose Product

\begin{tabular}{|l|c|c|c|c|}
\cline { 2 - 5 } \multicolumn{1}{c|}{} & (i), (ii), (iii) & (i)viscose & (ii) NCC & (iii) NFC \\
\cline { 2 - 5 } \multicolumn{1}{c|}{} & $(\mathrm{EOP})$ & $(\mathrm{PO})$ & $(\mathrm{PO})$ & $(\mathrm{PO})$ \\
\hline$t_{\mathrm{R}}(\mathrm{min})$ & 180 & 50.9 & 15.5 & 47.5 \\
\hline $\mathrm{T}\left({ }^{\circ} \mathrm{C}\right)$ & 80.0 & 97.2 & 99.4 & 96.8 \\
\hline $\mathrm{NaOH}(\mathrm{kg} / \mathrm{ADT})$ & 30.0 & 30.0 & 30.0 & 30.0 \\
\hline $\mathrm{H}_{2} \mathrm{O}_{2}(\mathrm{~kg} / \mathrm{ADT})$ & - & 30.0 & 40.0 & 30.0 \\
\hline Kappa No. & 1.86 & 0.500 & 1.38 & 1.00 \\
\hline Intrinsic viscosity $(\mathrm{mL} / \mathrm{g})$ & 550 & 509 & 500 & 516 \\
\hline$\alpha$-Cellulose $(\%)$ & 90.0 & 92.0 & 94.0 & 92.2 \\
\hline $\begin{array}{l}\text { Brightness } \\
(\% \text { GE) }\end{array}$ & 70.1 & 90.0 & 83.5 & 90.0 \\
\hline Costs & 13.23 & 7.10 & 2.30 & 6.53 \\
\hline Costs & $(€)$ & 136 & 51.3 & 127 \\
\hline Total Comicals $(€)$ & 144 & $\mathbf{1 4 3}$ & $\mathbf{5 3 . 6}$ & $\mathbf{1 3 4}$ \\
\hline
\end{tabular}

All calculated pulp grade costs were significantly lower than the current costs of the pulp mill, with $292.80 €$ for the (EOP) stage and $499.50 €$ for the (PO) stage (total 792.3 $€)$. In comparison with the pulp mill costs, the three proposed models significantly reduce both the energetic and the chemical costs of bleaching. The cheapest dissolving pulp grade is the NCC with an (EOP)(PO) bleach cost of $211 €$ per ton of air-dried pulp, whereas the viscose has a cost of $300 €$ per ton of air-dried pulp.

\section{CONCLUSIONS}

1. A multivariate statistical analysis was carried out to determine the main process variables affecting the quality of the dissolving pulp during (EOP)(PO) bleaching of the $\mathrm{Z}(\mathrm{EOP})(\mathrm{PO})$ bleaching sequence. The second-order response surface models 
developed from the factorial experiments for each bleaching stage fitted the pulp's bleaching behavior very well with coefficient of determination $\left(\mathrm{R}^{2}\right)$ values between $88.8 \%$ and $98.7 \%$.

2. Dosages of $\mathrm{NaOH}$ and $\mathrm{H}_{2} \mathrm{O}_{2}$ were the most influential variables of (EOP) stage, whereas reaction time and reaction temperature were the influential variables for (PO) stage (except for intrinsic pulp viscosity where time and $\mathrm{H}_{2} \mathrm{O}_{2}$ dosage were the most influential variables).

3. Three dissolving pulp grades were considered in the cost optimization of (EO)(PO) partial bleach sequence: one regenerated cellulose products (viscose) which is the most widely commercialized worldwide; and two novel products: nanocrystalline cellulose (NCC) and nanofibrillated cellulose (NFC), which are currently being investigated. A software program (GAMS) was used to obtain an optimization solution to the nonlinear problem developed that had equations describing the chemical and energy costs of (EO)(PO) partial bleach sequence. GAMS optimization of the three pulp grades indicated cost saving to the pulp mill of $62.2 \%, 73.4 \%$, and $63.3 \%$ for producing viscose, NCC, and NFC grades, respectively.

\section{ACKNOWLEDGMENTS}

The authors are grateful for the support of the European Union by the BRIGIT research project FP7-KBBE-2012-6-311935 under the seventh framework program (www.brigit-project.eu). In addition, A. Coz is grateful for the support from the FP1205 Cost Action entitled "Innovative applications of regenerated wood cellulose fibres".

\section{REFERENCES CITED}

Abraham, E., Deepa, B., Pothan, L. A., Jacob, M., Thomas, S., Cvelbar, U., and Anandjiwala, R. (2011). "Extraction of nanocellulose fibrils from lignocellulosic fibres: A novel approach," Carbohydr. Polym. 86(4), 1468-1475. DOI: 10.1016/j.carbpol.2011.06.034

Afsahi, G., Dimic-Misic, K., Gane, P., Budtova, T., Maloney, T., and Vuorinen, T. (2018). "The investigation of rheological and strength properties of NFC hydrogels and aerogels from hardwood pulp by short catalytic bleaching (Hcat)," Cellulose 25(3), 1637-1655. DOI: 10.1007/s10570-018-1678-6

Balea, A., Merayo, N., Fuente, E., Delgado-Aguilar, M., Mutje, P., Blanco, A., and Negro, C. (2016). "Valorization of corn stalk by the production of cellulose nanofibers to improve recycled paper properties," BioResources 11(2), 3416-3431. DOI: 10.15376/biores.11.2.3416-3431

Barbash, V. A., Yashchenko, O. V., and Shniruk, O. M. (2017a). "Preparation and properties of nanocellulose from organosolv straw pulp," Nanoscale Res. Lett. 12(1), 241-249. DOI: 10.1186/s11671-017-2001-4

Barbash, V., Yashchenko, O. and Kedrovska, A. (2017b). "Preparation and properties of nanocellulose from peracetic flax plp," J. Sci. Res. Rep. 16(1), 1-10. DOI: 10.9734/JSRR/2017/36571 
Bodhlyera, O., Zewotir, T., Ramroop, S., and Chunilall, V. (2015). "Analysis of the changes in chemical properties of dissolving pulp during the bleaching process using piecewise linear regression models," Cell. Chem. Technol. 49(3-4), 317-332.

Chen, C., Duan, C., Li, J., Liu, Y., Ma, X., Zheng, L., Stavik, J., and Ni, Y. (2016). "Cellulose (dissolving pulp) manufacturing processes and properties: A mini-review," BioResources 11(2), 5553-5564. DOI: 10.15376/biores.11.2.5553-5564

Duan, C., Li, J., Ma, X., Chen, C., Liu, Y., Stavik, J., Ni, Y. (2015). "Comparison of acid sulfite (AS)- and prehydrolysis kraft (PHK)-based dissolving pulps," Cellulose 22(6), 4017-4026.

Duan, C., Kumar Verma, S., Li, J., Ma, X., and Ni, Y. (2016). "Combination of mechanical, alkaline and enzymatic treatments to upgrade paper-grade pulp to dissolving pulp with high reactivity," Bioresource Technol. 200(Jan. 2016), 458-463. DOI: 10.1016/j.biortech.2015.10.067

Duan, C., Wang, X., Zhang, Y., Xu, Y., and Ni, Y. (2017). "Fractionation and cellulose treatment for enhancing the properties of kraft-based dissolving pulp," Bioresource Technol. 224(Jan. 2017), 439-444. DOI: 10.1016/j.biortech.2016.10.077

García, A., Gandini, A., Labidi, J., Belgacem, N., and Bras, J. (2016). "Industrial and crop wastes: A new source for nanocellulose biorefinery," Ind. Crop Prod. 93(25 Dec. 2016), 26-38. DOI: 10.1016/j.indcrop.2016.06.004

Gangwar, A. K., Tejo Prakash, N., and Prakash, R. (2016). "An eco-friendly approach: Incorporating a xylanase stage at various places in ECF and chlorine-based bleaching of eucalyptus pulp," BioResources 11(2), 5381-5388. DOI: 10.15376/biores.11.2.5381-5388.

García-Fuentevilla, L. L., Martin-Sampedro, R., Carbajo, J. M., Diaz, M. J., and Eugenio, M. E. (2015). "Enhancement of TCF and ECF bleaching processes by urea and enzymatic pretreatments: Optimization of a laccase-mediator pretreatment," BioResources 10(2), 2289-2304. DOI: 10.15376/biores.10.2.2289-2304.

Hutterer, C., Kliba, G., Punz, M., Fackler, K., and Potthast, A. (2017). "Enzymatic pulp upgrade for producing high-value cellulose out of a kraft paper pulp," Enzyme Microb. Technol. 102(July 2017), 67-73. DOI:10.1016/j.enzmictec.2017.03.014.

Iakovlev, M., Sixta, H., and van Heiningen, A. (2011). " $\mathrm{SO}_{2}$-ethanol-water (SEW) pulping: II. Kinetics for spruce, beech and wheat straw," J. Wood Chem. Technol. 31(3), 250266. DOI: $10.1080 / 02773813.2010 .523162$.

ISO 5351. (2010). "Pulps - Determination of limiting viscosity number in cupriethylenediamine (CED) solution," International Organization for Standardization, Geneva, Switzerland.

Kumar Chenna, N., Piovano, P., Järnefelt, C., and Vuorinen, T. (2016). “Organochlorine formation in tertiary amine catalyzed pulp bleaching," J. Wood Chem. Technol. 36(5), 318-328. DOI: 10.1080/02773813.2016.1148166

Kumar, H., and Christopher, L. (2017). "Recent trends and developments in dissolving pulp production and application," Cellulose 24(6), 2347-2365.

Li, Z., Li, J., Xu, J., and Mo, L.-h. (2015). "Clean bleaching engineering practices for bagasse pulp: Totally chlorine-free and elemental chlorine-free bleaching realized with the same production line," BioResources 10(2), 2667-2680. DOI: 10.15376/biores.10.2.2667-2680

Liu, Y., Shi, L., Cheng, D., and He, Z. (2016). "Dissolving pulp market and technologies: Chinese prospective - A mini-review," BioResources 11(3), 7902-7916. DOI: 10.15376/biores.11.3.7902-7916 
Llano, T., Rueda, C., Quijorna, N., Blanco, A., and Coz, A. (2012). "Study of the delignification of hardwood chips in a pulping process for sugar production," $J$ Biotechnol 162, 422-429. DOI: 10.1016/j.jbiotec.2012.06.030

Llano, T., García-Quevedo, N., Quijorna, N., Viguri, J. R., and Coz, A. (2015). "Evolution of lignocellulosic macrocomponentes in the wastewater streams of a sulfite pulp mill: A preliminary biorefining approach," J. Chem. 2015(2015), Article ID 102534, 10 pp. DOI: $10.1155 / 2015 / 102534$

Matin, M., Rahaman, M. M., Nayeem, J., Sarkar, M., and Jahan, S. M. (2015). “Dissolving pulp from jute stick," Carbohydr. Polym. 115(22 Jan. 2015), 44-48. DOI: 10.1016/j.carbpol.2014.08.090

MINCOTUR. (2018). Precio Neto de la Electricidad para Uso Doméstico y Uso Industrial. Ministry of Commerce Industry and Tourism of Spanish Government. (http://www.mincotur.gob.es/es-

ES/IndicadoresyEstadisticas/DatosEstadisticos/IV.\%20Energ\%C3\%ADa\%20y\%20e misiones/IV_12.pdf)

Montgomery, D.C. (1997). Design and Analysis of Experiments, $4^{\text {th }}$ Ed., John Wiley \& Sons, New York, NY. ISBN 0-471-15746-5

Quintana, E., Valls, C., Vida, T., and Roncero, M. B. (2015a). "Comparative evaluation of the action of two different endoglucanases. Part I: On a fully bleached, commercial acid sulfite dissolving pulp," Cellulose 22(3), 2067-2079. DOI: 10.1007/s10570-0150623-1

Quintana, E., Valls, C., Vidal, T., and Roncero, M.B. (2015b). "Comparative evaluation of the action of two different endoglucanases. Part II: On a biobleached acid sulphite pulp," Cellulose 22(3), 2081-2093. DOI: 10.1007/s10570-015-0631-1

RISI. (2017). Outlook for the Global Dissolving Pulp Market 2016 (Special Market Analysis Study), RISI, Bedford, MA, USA, (https: //www.risiinfo.com/product/outlook-for-the-global-dissolving-pulp-market-2016/)

Sehaqui, H., Allais, M., Zhou, Q., and Berglund, L. A. (2011). "Wood cellulose biocomposites with fibrous structures at micro- and nano-scale," Compos. Sci. Technol. 71(3), 382-387. DOI: 10.1016/j.compscitech.2010.12.007

Sixta, H. (2000). "Comparative evaluation of TCF bleached harwood dissolving pulps," Lenzinger Ber. 79, 119-128.

Sixta, H. (2006). "Handbook of Pulp," vol. 1. First ed. WILEY-VCH Verlag GmbH \& Co. KGaA, Weinheim, Germany.

Sixta, H., Roselli, A., Hummel, M., and Ruuttunen, K. (2013). "Advances in dissolving pulp technology," in: 6th International Colloquium on Eucalyptus Pulp, Colonia del Sacramento, Urugay.

Sixta, H., Iakovlev, M., Testova, L., Roselli, A., Hummel, M., Borrega, M., van Heiningen, A., Froschauer, C., and Schottenberger, H. (2013). "Novel concepts of dissolving pulp production," Cellulose 20(4), 1547-1561. DOI: 10.1007/s10570-013-9943-1.

Sixta, H., and Schild, G. (2009). "A new generation kraft process," Lenzinger Ber. 87, 2637.

TAPPI T203 cm-99. (1999). "Alpha-, beta- and gamma-cellulose in pulp," TAPPI Test Methods, TAPPI Press, Atlanta, GA.

TAPPI T205 sp-02. (2002). "Forming handsheets for physical tests of pulp," TAPPI Test Methods, TAPPI Press, Atlanta, GA.

TAPPI T452 om-02. (2002). "Brightness of pulp, paper, and paperboard (Directional reflectance at $457 \mathrm{~nm})$," TAPPI Test Methods, TAPPI Press, Atlanta, GA. 
TAPPI UM 246. (1991). "Micro kappa number," TAPPI Useful Methods 1991, TAPPI Press, Atlanta, GA, pp. 43-44.

Tonoli, G. H. D., Teixeira, E. M., Corrêa, A. C., Marconcini, J. M., and Caixeta, L. A. (2012). "Cellulose micro/nanofibers from Eucalyptus kraft pulp: Preparation and properties," Carbohydr. Polym. 89(1), 80-88. DOI: 10.1016/j.carbpol.2012.02.052

Veisi, A., and Mahdavi, S. (2016). "Mixing bleached white poplar and wheat straw chemimechanical pulps to improve the mechanical and optical characteristics," BioResources 11(2), 2987-2997. DOI: 10.15376/biores.11.2.2987-2997

Wang, X., Cui, X., and Zhang, L. (2012). "Preparation and characterization of lignincontaining nanofibrillar cellulose," Procedia Environ. Sci. 16(2012), 125-130. DOI: 10.1016/j.proenv.2012.10.017

Yaqoob, N., Stack, K., and Nguyen, K. L. (2010). “TCF bleaching of eucalypt kraft pulp with oxone," Appita Journal 63(5), 391-386.

Yao, S., Gao, C., Zhu, H., Zhang, Y., Wang, S., and Qin, C. (2016). "Effects of additives on adsorbable organic halide reduction in elemental chlorine-free bleaching of bagasse kraft pulp,” BioResources 11(1), 996-1006. DOI: 10.15376/biores.11.1.996-1006.

Zhao, L., Yuan, Z., Kapu, N. S., Chang, X. F., Beatson, R., Trajano, H. L., and Martinez, D. M. (2017). "Increasing efficiency of enzymatic hemicellulose removal from bamboo for production of high-grade dissolving pulp," Bioresource Technol. 223(Jan. 2017), 40-46. DOI: 10.1016/j.biortech.2016.10.034

Zhou, X. F. (2015). "Dissolving lignin components in spent liquor of simple inorganic complex bleaching eucalyptus pulp," Drewno. 58(194), 75-87. DOI: 10.12841/wood.1644-3985.071.06

Article submitted: April 10, 2018; Peer review completed: June 15, 2018; Revised version received: June 29, 2018; Accepted: July 6, 2018; Published: July 16, 2018.

DOI: 10.15376/biores.13.3.6642-6662 